\title{
Immune modulatory function of abundant immune-related microRNAs in microvesicles from bovine colostrum
}

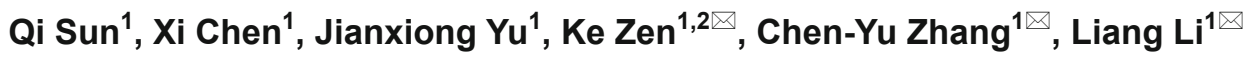 \\ 1 Jiangsu Engineering Research Center for microRNA Biology and Biotechnology, State Key Laboratory of Pharmaceutical \\ Biotechnology, Nanjing University School of Life Sciences, Nanjing 210093, China \\ ${ }^{2}$ Department of Virology, University of California School of Public Health, Berkeley, CA 94720, USA. \\ \ Correspondence: kzen@nju.edu.cn (K. Zen), cyzhang@nju.eud.cn (C.-Y. Zhang), lijing@sibs.ac.cn (L. Li) \\ Received November 28, 2012 Accepted December 19, 2012
}

\begin{abstract}
Colostrum provides essential nutrients and immunologically active factors that are beneficial to newborns. Our previous work demonstrated that milk contains large amounts of miRNA that is largely stored in milk-derived microvesicles (MVs). In the present study, we found that the MVs from colostrum contain significantly higher levels of several immune-related miRNAs. We hypothesized that the colostrum MVs may transfer the immune-related miRNAs into cells, which contribute to its immune modulatory feature. We isolated colostrum MVs by ultracentrifugation and demonstrated several immune modulation features associated with miRNAs. We also provide evidence that the physical structure of milk-derived MVs is essential for transfer miRNAs and following immune modulation effect. Moreover, we found that colostrum powder-derived MVs also contains higher levels of immune-related miRNAs that display similar immune modulation effects. Taken together, these results show that MV-containing immunerelated miRNAs may be a novel mechanism by which colostrum modulates body immune response.
\end{abstract}

KEYWORDS colostrum, miRNAs, microvesicles, immune modulation

\section{INTRODUCTION}

Maternal milk is the primary source of nutrition for newborns. Compared to mature milk, colostrum is thought to have more value for newborn immunity and health (Agarwal et al., 2011). Colostrum may possess more immune-regulatory properties to strengthen the immunity of newborns and protect them against early infections (Feng et al., 2011) because newborns not fed colostrum have a higher incidence of gastrointestinal and respiratory infections (Honorio-Franca et al., 1997, 2001). Indeed, substantial evidence showed that colostrum contains more immune-regulatory agents. For instance, human colostrum contain large quantities of secretary (s) IgA, which can bind to pathogens and protect the infant's cells (Macchiaverni et al., 2011). Colostrum also contains significant amounts of lysozyme and oligosaccharides, which have antimicrobial effects (Patiroglu and Kondolot, 2011), and there are several additional immune regulatory components in milk that may be helpful to the early development of the immune system.

MicroRNAs (miRNAs) are endogenous non-coding RNAs, 19-24 nucleotides in length, which play significant roles in regulating gene expression (Chen et al., 2008; Huang et al., 2010;). Specific miRNAs that play important roles in a wide range of physiological and pathological processes in mammals may also be involved in the control of immunologic reactions ( $\mathrm{El}$ Gazzar and McCall, 2012). There is evidence that showed that miRNAs directly regulate the expression of cytokines and immune cell function (Sharma et al., 2009; Huang and He, 2010); furthermore, it is reported that specific miRNA expression is essential for resistance to certain viruses (Fahim et al., 2012).

It has recently been reported that the exosomal vesicles secreted by mast cells, glioblastoma cells, and embryonic stem cells contained mRNA and miRNA that could be transferred to and function in neighboring cells (Skog et al., 2008; Zhang et al., 2010). More interestingly, exosome-like vesicle has been identified in human milk and bovine milk, indicating the possible involvement of milk-derived vesicles in immune regulation in infants (Admyre et al., 2007; Hata et al., 2010). It is possible that miRNAs may be delivered via milk derived vesicles, as there is evidence that exogenous miRNAs can enter the body 
through the diet (Zhang et al., 2012). Our previous studies have shown that miRNAs are stably present in many kinds of body fluids, including serum, cell culture supernatants and raw milk (Chen et al., 2008, 2010). Our Solexa data demonstrated that colostrum contains higher levels of miRNAs than mature milk, especially immune-related miRNAs (Chen et al., $2008,2010)$. In the present study, we compared the miRNA expression level between colostrum and mature milk by qRTPCR and detected a higher expression of immune-related miRNAs in colostrum. Further investigation showed that a large proportion of these miRNAs are present in milk-derived vesicles, which had a significant impact on the cellular function of RAW264.7 macrophages. Vesicles from raw milk, especially colostrum, modulated cytokine production after stimulation with a low concentration of LPS and increased the cell migration and phagocytosis of RAW264.7 macrophages, effects that were strongly compromised when the vesicle structure was destroyed. Further investigation provides evidence that miRNAs in colostrum vesicles can be delivered into cultured cells, which is associated with its immune modulatory function. Moreover, the colostrum powder-derived vesicles also demonstrated similar immune modulatory features. Taken together, our results suggest that colostrum contain more immune-related miRNAs than milk-derived vesicles and may regulate immune cell function by transferring miRNA to immune cells.

\section{RESULTS}

Immune-related miRNA expression in colostrum and mature milk

Based on the previous Solexa results, we have selected several immune-related miRNAs and compared their levels between the same volume of mature milk and colostrum using qRT-PCR (Chen et al., 2008). The molar abundance of each miRNA was calculated based on the standard curve from different concentration of synthetic miR-16. We picked up miRNAs that were significantly higher in colostrum using the following criteria: (1) the fold change of miRNA expression level is more than 4 and (2) the expression level of miRNAs is more than 10-14 molar/mL milk (Table 1). Seven miRNAs, miR-24, miR-30d, miR-93, miR-106a, miR-181a, miR-200a and miR451 and were selected and all of them have higher sequencing frequency in colostrum analyzed by Solexa. In addition, five (miR-24, miR-93, miR-106a, miR-181a and miR-451) out of those seven miRNAs were significantly higher in colostrum in the earlier soloxa data (Table 2).

\section{Relative miRNA expression in colostrum- and mature} milk-derived vesicles

To examine whether miRNAs are stored in colostrum-derived vesicles, we purified vesicles by differential ultracentrifugation (Hata et al., 2010) and prepared the samples for EM imaging, which demonstrated vesicle-like structures (Fig. 1A left panel). There are no differences in ultrastructure of the vesicles be- tween colostrum and mature milk. Next, we assessed the distribution of miRNAs in the supernatant or pellet of colostrum after differential ultracentrifugation and found that most of the miRNAs were enriched in the $100,000 \mathrm{~g}$ pellet (Fig. 1B and 1C; Table 3).

Because the majority of milk miRNAs were found in the milk-derived vesicles, we further investigated the levels of those seven miRNAs in different groups of purified vesicles. First, we evaluated the protein contents of both milk derived vesicles samples which showed no significant differences with the concentration around $5 \mu \mathrm{g} / \mu \mathrm{L}$ in PBS solution, which equals to $50 \mu \mathrm{g} / \mathrm{mL}$ of original volume of milk sample (Fig. 1D). Next, we analyzed levels of seven miRNAs in both groups of milk derived vesicles and found that the colostrum vesicles contain higher levels (1.9-10.2 folds change) of those seven miRNAs (miR-24, miR-30d, miR-93, miR-106a, miR-181a, miR-200a and miR-451) compared to the same amount of mature milk vesicles counted by protein concentration, which agrees with the results demonstrated in raw milk (Fig. 1E). Furthermore, we also calculated the amount of these miRNAs in molar abundance between milk vesicles and cultured cells showing that several miRNAs levels in colostrum vesicles are relatively higher than those in RAW cells (Table 4).

\section{Milk-derived vesicles showed the ability to carry and deliver miRNAs into cultured cells}

Several studies have provided strong evidence that microvesicles are able to deliver small molecules, such as miRNAs or mRNA, into cells (Skog et al., 2008; Zhang et al., 2010). To investigate whether milk derived vesicles can transfer cargos into cultured cells we labeled milk derived vesicles with red fluorescence before co-incubation with RAW cells. We found those red fluorescence labeled vesicles can enter into cultured cells while no labeled vesicles were found when the membrane structure of vesicles was impaired by ultrasonication (Fig. $1 \mathrm{~A}$ and $1 \mathrm{~F}$ ). In addition, bovine specific gene transcripts were clearly amplified only when RAW264.7 cells were incubated with milk-derived vesicles (Fig. 1G). These data suggest that milk derived vesicles can deliver small molecules into cultured cells. We further assessed the levels of seven miRNAs after co-incubation with mature milk or colostrum-derived vesicles and found that the miR-106a, miR-181a and miR-451 level were significantly increased in the colostrum vesicles-treated cells, while the other miRNAs remained unchanged, which may be the result of high endogenous background (Fig. 1H, Table 4). By assessing the cellular pre-miRNAs level, we found that the pre-miRNAs are not significantly elevated in RAW264.7 cells (Fig. 1I). Furthermore, those increased miRNAs showed dose-dependent response in RAW264.7 cells when treating with different concentration of colostrum vesicles (Fig. 1J). Together, these data indicates that the increased level of miRNAs originated from the colostrum derived vesicles. It is reported that lipoprotein complex may be co-purified with microvesicles through ultracentrifugation and there are evidences that such 
Table 1. Molar abundance and fold change of miRNAs between the same volume of colostrum and mature milk

\begin{tabular}{|c|c|c|c|}
\hline & $\begin{array}{l}\text { Colostrum } \\
\text { (molar/mL colostrum) }\end{array}$ & $\begin{array}{l}\text { Mature milk } \\
\text { (molar/mL mature milk) }\end{array}$ & $\begin{array}{l}\text { Fold change } \\
\text { (Colostrum/Mature milk) }\end{array}$ \\
\hline let-7b & $2.40 \pm 0.11 \times 10^{-12}$ & $3.21 \pm 0.47 \times 10^{-12}$ & 0.75 \\
\hline miR-16 & $1.09 \pm 0.21 \times 10^{-12}$ & $6.03 \pm 1.00 \times 10^{-13}$ & 1.82 \\
\hline miR-18a & $3.18 \pm 0.38 \times 10^{-15}$ & $7.94 \pm 1.65 \times 10^{-16}$ & 4.01 \\
\hline miR-19a & $\mathrm{N} / \mathrm{A}$ & $4.11 \pm 0.90 \times 10^{-14}$ & $N / A$ \\
\hline miR-20a & $6.78 \pm 2.07 \times 10^{-13}$ & $6.72 \pm 1.03 \times 10^{-13}$ & 1.01 \\
\hline $\mathrm{miR}-21$ & $4.48 \pm 0.26 \times 10^{-14}$ & $3.50 \pm 0.49 \times 10^{-14}$ & 1.28 \\
\hline miR-24 & $5.70 \pm 0.26 \times 10^{-14}$ & $1.37 \pm 0.20 \times 10^{-14}$ & $4.15^{*}$ \\
\hline miR-27a & $7.52 \pm 0.39 \times 10^{-14}$ & $7.26 \pm 0.63 \times 10^{-14}$ & 1.04 \\
\hline miR-29a & $1.75 \pm 0.02 \times 10^{-13}$ & $8.04 \pm 1.34 \times 10^{-14}$ & 2.19 \\
\hline miR-30d & $1.74 \pm 0.12 \times 10^{-13}$ & $2.83 \pm 0.43 \times 10^{-14}$ & $6.15^{*}$ \\
\hline miR-31 & $5.39 \pm 0.70 \times 10^{-15}$ & $4.24 \pm 1.02 \times 10^{-15}$ & 1.27 \\
\hline $\mathrm{miR}-32$ & $1.95 \pm 0.03 \times 10^{-14}$ & $1.07 \pm 0.17 \times 10^{-14}$ & 1.82 \\
\hline miR-93 & $2.36 \pm 0.25 \times 10^{-13}$ & $3.25 \pm 0.35 \times 10^{-14}$ & $7.25^{*}$ \\
\hline miR-100 & $1.14 \pm 0.03 \times 10^{-15}$ & $2.17 \pm 0.31 \times 10^{-15}$ & 0.53 \\
\hline miR-106a & $3.51 \pm 0.24 \times 10^{-13}$ & $8.47 \pm 1.63 \times 10^{-14}$ & $4.15^{*}$ \\
\hline $\mathrm{miR}-125 \mathrm{~b}$ & $9.70 \pm 2.87 \times 10^{-16}$ & $N / A$ & N/A \\
\hline$m i R-142-5 p$ & $6.41 \pm 0.705 \times 10^{-15}$ & N/A & $\mathrm{N} / \mathrm{A}$ \\
\hline $\operatorname{miR}-146 a$ & $2.14 \pm 0.12 \times 10^{-14}$ & $3.18 \pm 0.45 \times 10^{-14}$ & 0.67 \\
\hline miR-150 & $2.64 \pm 0.09 \times 10^{-14}$ & $4.05 \pm 0.38 \times 10^{-14}$ & 0.65 \\
\hline miR-155 & $7.83 \pm 0.27 \times 10^{-15}$ & $1.42 \pm 0.10 \times 10^{-14}$ & 0.55 \\
\hline miR-181a & $7.88 \pm 0.74 \times 10^{-14}$ & $1.64 \pm 0.18 \times 10^{-14}$ & $4.79^{*}$ \\
\hline miR-200a & $3.97 \pm 0.25 \times 10^{-13}$ & $9.21 \pm 1.31 \times 10^{-14}$ & $4.32^{*}$ \\
\hline miR-210 & $2.84 \pm 0.06 \times 10^{-14}$ & $4.40 \pm 1.10 \times 10^{-14}$ & 0.65 \\
\hline miR-214 & N/A & $3.77 \pm 0.54 \times 10^{-14}$ & $N / A$ \\
\hline miR-221 & $2.70 \pm 0.07 \times 10^{-14}$ & $7.33 \pm 1.67 \times 10^{-14}$ & 0.37 \\
\hline miR-223 & $7.05 \pm 0.24 \times 10^{-13}$ & $7.66 \pm 1.02 \times 10^{-13}$ & 0.92 \\
\hline miR-451 & $2.07 \pm 0.42 \times 10^{-13}$ & $1.05 \pm 0.26 \times 10^{-14}$ & $19.68^{*}$ \\
\hline
\end{tabular}

Molar abundance of each miRNAs was calculated based on the standard curve from different concentration of synthetic miR-16.

* miRNAs selected according to the criteria

Table 2. Solexa data of sequencing frequency of seven miRNAs in colostrum and mature milk from the previous work (Chen et al., 2010)

\begin{tabular}{|llll}
\hline & Colostrum & Mature milk & Fold change \\
\hline miR-24 & 10633 & 909 & 11.7 \\
\hline miR-30d & 18922 & 14089 & 1.34 \\
\hline miR-93 & 3919 & 175 & 22.4 \\
\hline miR-106a & 207 & 5 & 41.4 \\
\hline miR-181a & 6255 & 1023 & 6.11 \\
\hline miR-200a & 1582 & 940 & 1.68 \\
\hline miR-451 & 25 & 2 & 12.5 \\
\hline
\end{tabular}

Five out seven miRNAs have higher copy number (>2 folds) in colostrum than those in mature milk.

complex can also carry and deliver miRNAs (Vickers et al., 2011). To test whether these miRNAs are associated with such complex, we treated $70,000 \mathrm{~g}$ supernatant of colostrum with or without proteinase $\mathrm{K}\left(50 \mu \mathrm{g} / \mathrm{mL}, 55^{\circ} \mathrm{C}, 2 \mathrm{~h}\right)$ before we collected the vesicle pellet by $100,000 \mathrm{~g}$ centrifugation, which can degrade protein complex and release associated miRNAs. We assessed the miRNAs levels and found no significant differences between two groups of vesicles, which indicated that most part of the miRNAs were in colostrums vesicles (Fig. 2A). Notably, the elevation of mature miRNAs in RAW cells was blocked by destroying the physical structure of the colostrum vesicles after ultrasonication (Fig. $1 \mathrm{H}$ ). To exclude the possibility that ultrasonication may impair the miRNAs integrity, we measured the miRNAs level of colostrum vesicles treated with ultrasonication at different time. We found that miRNAs levels were not significantly changed immediately after ultrasonication while there is a slight decrease of miR-93 and miR-181a $24 \mathrm{~h}$ after the treatment, which suggests that ultrasonication cannot destroy miRNAs while membrane structure may con- 




Colostrum vesicles

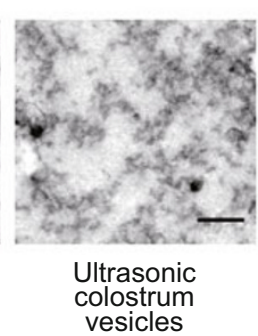

- 35,000 g supernatant $\square 70,000 \mathrm{~g}$ supernatant

1.4 ㅁ 100,000 g supernatant

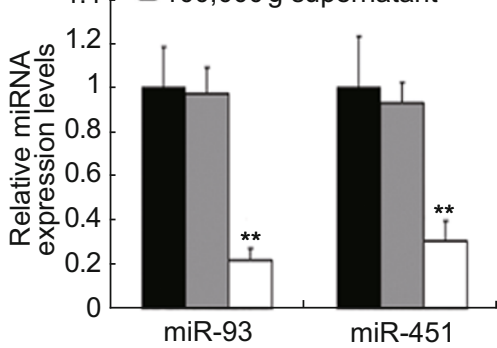

C





$\mathrm{H}$



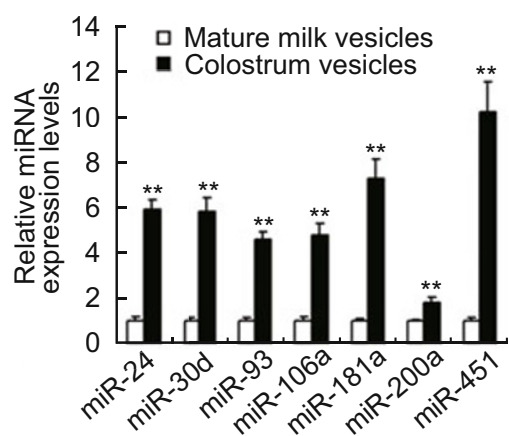



$\mathrm{F}$
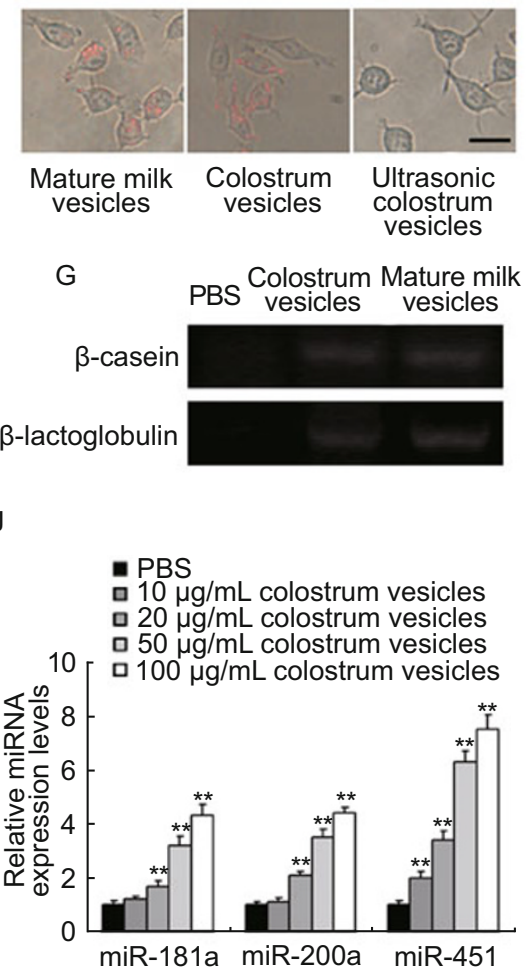

Figure 1. Distribution of miRNAs in various colostrum fractions and the delivery of miRNAs to macrophages by MVs. (A) EM images of purified colostrum vesicles and ultrasonic colostrum vesicles by 100,000 $\mathrm{g}$ ultracentrifugation, arrows: structures of colostrum vesicles, scale bar $=50 \mathrm{~nm}$. (B) Relative miR-93 and miR-451 levels in each supernatant separated by differential ultracentrifugation. (C) Relative miR-93 and miR-451 levels in each pellet separated by differential ultracentrifugation. (D) Protein concentration of colostrum vesicles and mature milk vesicles showed no difference. Vesicles purified from $100 \mathrm{~mL}$ milk were suspended in $1 \mathrm{~mL}$ PBS and the protein concentration of vesicles in PBS is about $5 \mu \mathrm{g} / \mu \mathrm{L}$. (E) Relative miRNAs levels between colostrum vesicles and mature milk vesicles; (F) Red fluorescence labeled vesicles in cultured RAW cells treated with different groups of milk vesicles, scale bar $=10 \mu \mathrm{m}$. (G) Bovine specific gene transcripts amplified in RAW cells incubated with or without milk-derived vesicles. $(\mathrm{H})$ Relative miRNAs levels in RAW264.7 cells after co-incubation with different milk-derived vesicles. Colostrum vesicles increase the cellular level of miR-106a, miR-181 and miR451 to $281 \pm 41 \%, 329 \pm 54 \%$ and $521 \pm 82 \%$, respectively. (I) Relative pre-miRNAs levels in RAW264.7 cells after co-incubation with different groups of milk-derived vesicles. $(\mathrm{J})$ Relative miRNAs levels in RAW264.7 cells after co-incubation with different concentration of colostrum vesicles ${ }^{* \star} P<0.01$.

tribute to the protection of miRNAs integrity (Fig. 2B). Together, these results indicate that membrane structure of the colostrum vesicles is essential for transferring miRNAs from vesicles into cultured cells. To determine whether mature milk vesicles have the same ability to transfer miRNAs as colostrum vesicles, we further assessed the level of let-7b, miR-16 and miR-20a in RAW cells after co-incubation with milk derived vesicles. We demonstrated that miR-20a was increased in both groups of 
Table 3. Molar abundance of miRNAs in the supernatant or pellet of colostrum after differential ultracentrifugation correspond to (Fig. 1B and 1C)

\begin{tabular}{lllll}
\hline & & $\begin{array}{l}35,000 \mathrm{~g} \\
(\mathrm{molar} / \mathrm{mL} \text { colostrum })\end{array}$ & $\begin{array}{l}70,000 \mathrm{~g} \\
(\mathrm{molar} / \mathrm{mL} \text { colostrum })\end{array}$ & $\begin{array}{l}100,000 \mathrm{~g} \\
(\mathrm{molar} / \mathrm{mL} \text { colostrum })\end{array}$ \\
\hline miR-93 & Supernatant & $1.85 \pm 0.35 \times 10^{-13}$ & $1.81 \pm 0.22 \times 10^{-13}$ & $4.18 \pm 0.98 \times 10^{-14}$ \\
& Pellet & $1.89 \pm 0.55 \times 10^{-14}$ & $2.83 \pm 1.02 \times 10^{-14}$ & $1.21 \pm 0.15 \times 10^{-13}$ \\
\multirow{2}{*}{ miR-451 } & Supernatant & $2.82 \pm 0.66 \times 10^{-13}$ & $2.63 \pm 0.25 \times 10^{-13}$ & $8.71 \pm 2.75 \times 10^{-14}$ \\
& Pellet & $3.47 \pm 0.79 \times 10^{-14}$ & $6.26 \pm 1.39 \times 10^{-14}$ & $1.53 \pm 0.31 \times 10^{-13}$ \\
\hline
\end{tabular}

Table 4. Molar abundance of miRNAs in colostrum vesicles, mature milk vesicles and cultured RAW264.7 cells

\begin{tabular}{llll}
\hline & $\begin{array}{l}\text { Colostrum vesicles } \\
\text { (molar/100 } \mu \mathrm{g} \text { vesicle })\end{array}$ & $\begin{array}{l}\text { Mature milk vesicles } \\
\text { (molar/100 } \mu \mathrm{g} \text { vesicle) }\end{array}$ & $\begin{array}{l}\text { RAW cells } \\
\text { (molar/5 } \times 10^{5} \text { cells in 3.5-cm dish with 2 mL medium) }\end{array}$ \\
\hline miR-24 & $1.10 \pm 0.07 \times 10^{-13}$ & $1.91 \pm 0.31 \times 10^{-14}$ & $6.39 \pm 0.39 \times 10^{-12}$ \\
\hline miR-30d & $2.42 \pm 0.25 \times 10^{-13}$ & $4.23 \pm 0.64 \times 10^{-14}$ & $3.22 \pm 0.19 \times 10^{-12}$ \\
\hline miR-93 & $3.23 \pm 0.21 \times 10^{-13}$ & $7.09 \pm 1.04 \times 10^{-14}$ & $8.50 \pm 0.44 \times 10^{-13}$ \\
\hline miR-106a & $5.31 \pm 0.56 \times 10^{-13}$ & $1.13 \pm 0.16 \times 10^{-13}$ & $8.63 \pm 0.52 \times 10^{-14}$ \\
\hline miR-181a & $1.38 \pm 0.14 \times 10^{-13}$ & $1.83 \pm 0.08 \times 10^{-14}$ & $2.25 \pm 0.12 \times 10^{-14}$ \\
\hline miR-200a & $5.74 \pm 0.47 \times 10^{-13}$ & $3.12 \pm 0.06 \times 10^{-13}$ & $2.77 \pm 0.09 \times 10^{-11}$ \\
\hline miR-451 & $3.22 \pm 0.42 \times 10^{-13}$ & $3.17 \pm 0.36 \times 10^{-14}$ & $3.34 \pm 0.28 \times 10^{-14}$ \\
\hline
\end{tabular}

The amount of miR-106a, miR-181a and miR-451 in colostrum vesicles is higher than those in RAW cells.

A

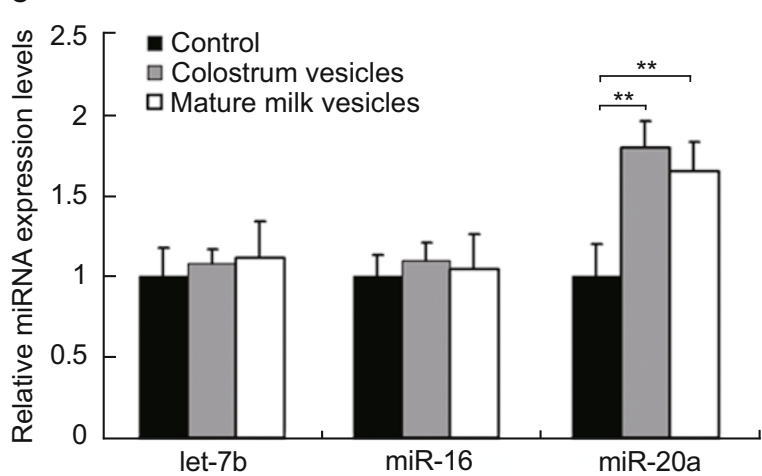

cells which suggested that mature milk vesicles can also deliver miRNAs into cells as colostrum vesicles (Fig. 2C). Among them, let-7b and miR-16 did not change significantly, which may be the result of high endogenous background in cellular miRNAs (Table 5).

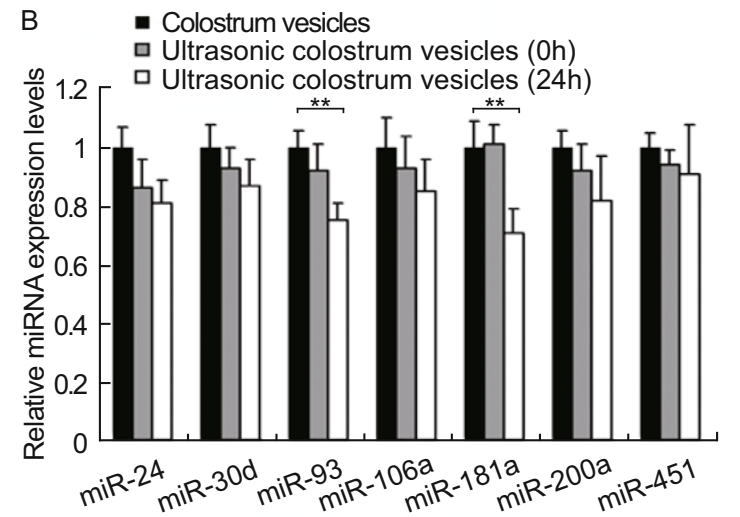

Figure 2. Quantitative analysis of miRNAs levels. (A) Relative miRNAs levels between two groups of vesicles from colostrum pretreated with or without proteinase K. (B) Relative miRNAs levels in different groups of colostrum vesicles treated with or without ultrasonication. (C) Relative miRNAs levels in RAW cells treated with PBS, colostrum vesicles and mature milk vesicles respectively. miR-20a increased in both group of cultured cells treated with milk derived vesicles while let $7 \mathrm{~b}$ and miR-16 remained unchanged. ${ }^{* *} P<0.01$.

\section{Colostrum-derived vesicles showed several immune modulatory features}

It has been demonstrated that increases in miRNA can affect cytokine production and inflammatory responses in 
Table 5. Molar abundance of miRNAs in milk derived vesicles and RAW cells

\begin{tabular}{llll}
\hline & $\begin{array}{l}\text { Colostrum vesicles } \\
\text { (molar/100 } \mu \mathrm{g} \text { vesicle })\end{array}$ & $\begin{array}{l}\text { Mature milk vesicles } \\
(\text { molar/100 } \mu \mathrm{g} \text { vesicle })\end{array}$ & $\begin{array}{l}\text { RAW cells } \\
\text { (molar/5 } \times 10^{5} \text { cells in 3.5-cm dish with 2 mL medium) }\end{array}$ \\
\hline let-7b & $4.24 \pm 0.37 \times 10^{-12}$ & $4.85 \pm 0.33 \times 10^{-12}$ & $6.53 \pm 0.32 \times 10^{-10}$ \\
\hline miR-16 & $2.12 \pm 0.18 \times 10^{-12}$ & $1.81 \pm 0.25 \times 10^{-12}$ & $5.32 \pm 0.27 \times 10^{-11}$ \\
\hline miR-20 & $1.40 \pm 0.09 \times 10^{-12}$ & $1.53 \pm 0.16 \times 10^{-12}$ & $3.30 \pm 0.21 \times 10^{-13}$ \\
\hline
\end{tabular}

The endogenous background of let7b and miR-16 is much higher while miR-20a is relatively lower compared to the miRNAs level in milk derived vesicles.

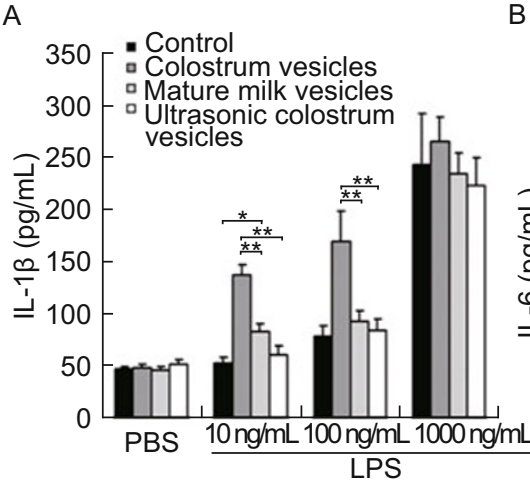

D
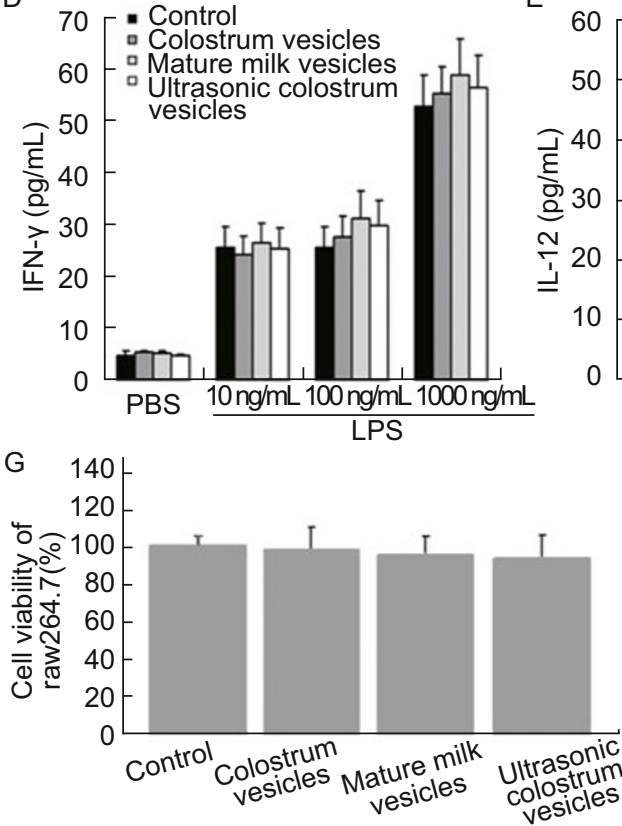

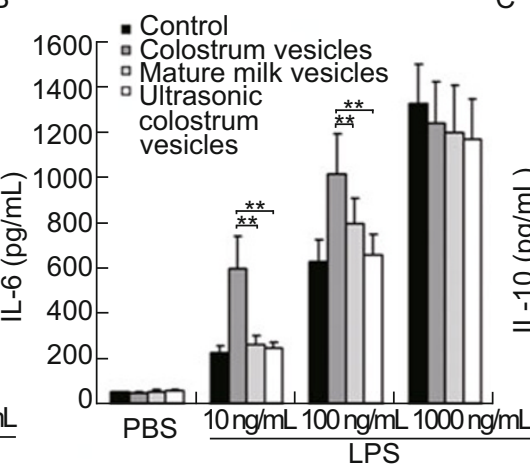

$\mathrm{E}$
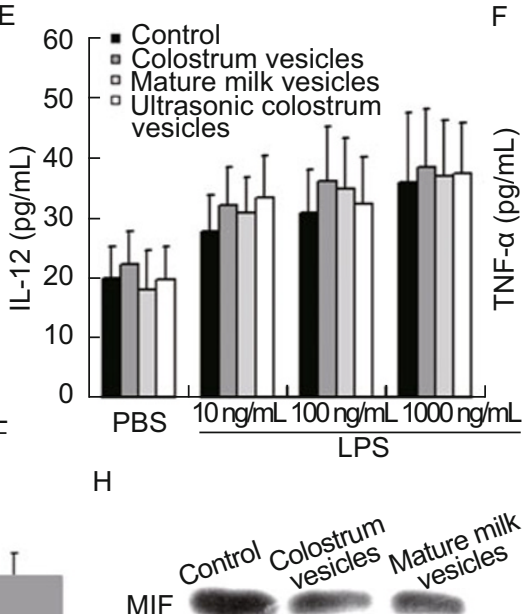

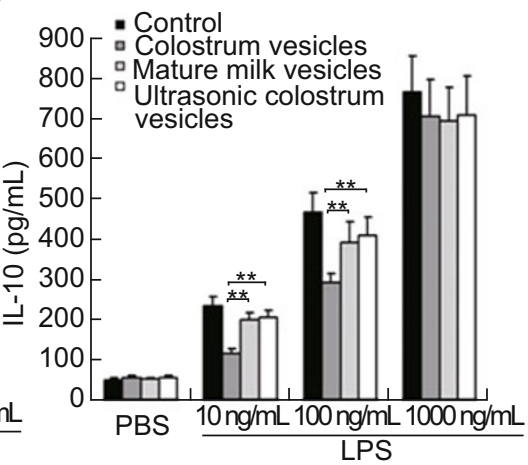

4500 - Control

4000 - Colostrum vesicles

4000 - Mature milk vesicles

3500- Ultrasonic colostrum
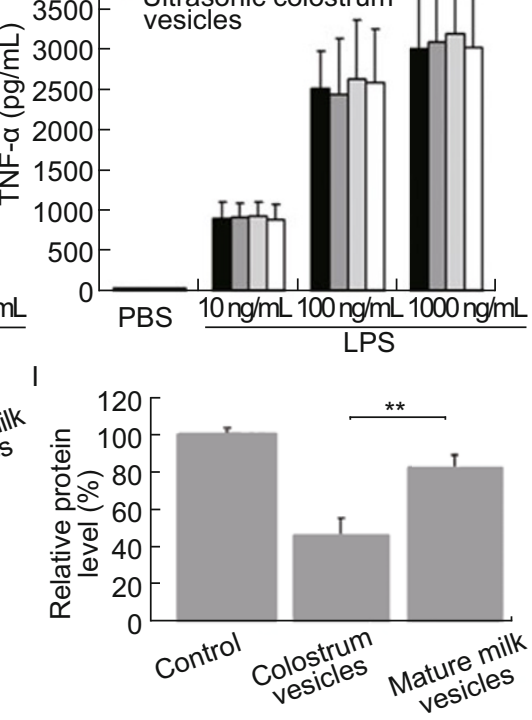

Figure 3. Colostrum vesicles demonstrated regulatory effects on cytokine production that were associated with its membrane structure. (A-F) Levels of different cytokines secreted by RAW264.7 cells treated with different groups of milk-derived vesicles. (G) Cell proliferation rate measured by cck-8. (H) Western blot of MIF and GAPDH in RAW264.7 cells. (I) Relative protein levels of MIF/GAPDH in RAW264.7 cells. ${ }^{*} P<0.05 ;{ }^{* \star} P<0.01$.

macrophages. For instance, miR-106a directly targets IL-10, whereas macrophage migration inhibitor factor (MIF) is the target gene of miR-451 (Bandres et al., 2009; Sharma et al., 2009). In addition, miR-181a is suggested to be involved in the anti-inflammatory effect of macrophages (Sonkoly et al., 2008). Based on the potential function of the increased miRNAs, we used the macrophage cell line RAW264.7 to test whether milk- derived vesicles can affect cellular immune functions, including immune cell proliferation, cytokine production, phagocytosis and cell migration. First, we demonstrated that the pretreatment with colostrum vesicles showed significant effects in regulating cytokine production in RAW264.7 cells following stimulation using a low concentration of LPS (10 and $100 \mathrm{ng} / \mathrm{mL}$ ). Colostrum vesicles significantly increased the IL- 1 and IL-6 
A

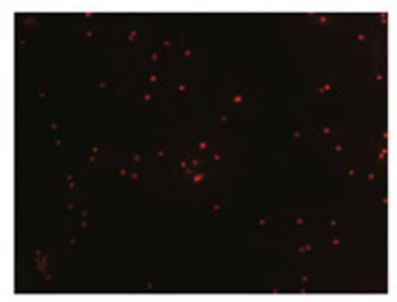

B
Colostrum vesicles

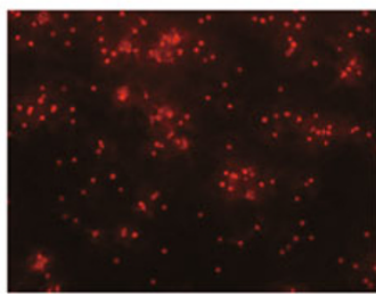

Colostrum vesicles
Mature milk vesicles

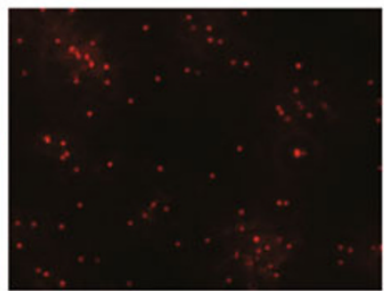

Mature milk vesicles
Ultrasonic colostrum vesicles

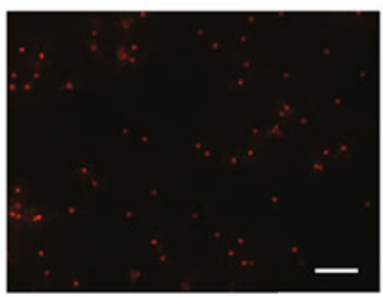

Ultrasonic colostrum vesicles

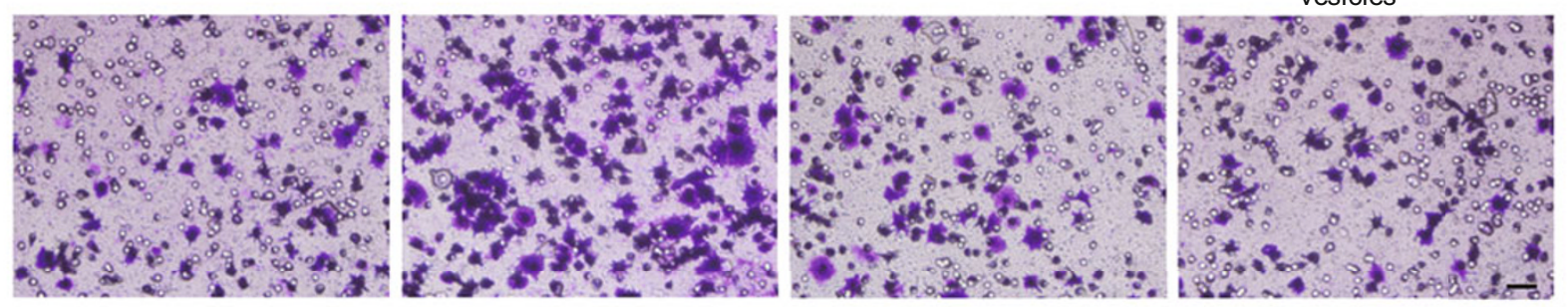

C



D

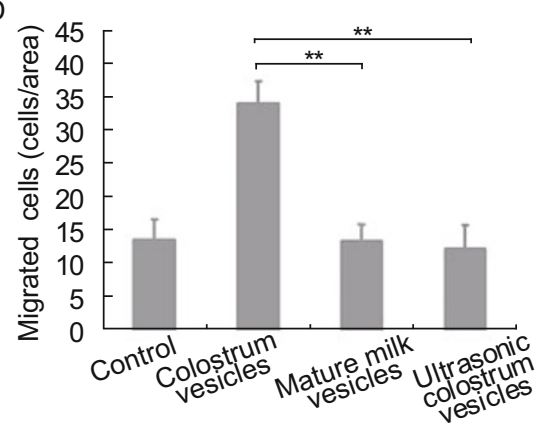

Figure 4. Colostrum vesicles demonstrated regulatory effects on phagocytosis and cell migration that were associated with its membrane structure. (A and C) Fluorescence image and intensity of phagocytosis rates of RAW264.7 cells treated with different groups of milk-derived vesicles, scale bar $=10 \mu \mathrm{m} ;(B$ and $D)$ Cell migration images and the migratory ability of each group are shown, scale bar $=30 \mu \mathrm{m} .{ }^{*} P<0.05 ;{ }^{* *} P<0.01$.

production and decreased the IL-10 level, though IFN-y, IL-12 and TNFa levels remained unchanged (Fig. 3A-F). However, these changes disappeared when the RAW264.7 cells were treated with no LPS stimulation or after the exposure to a higher concentration of LPS ( 0 or $1000 \mathrm{ng} / \mathrm{mL}$ ). We also provide evidence that milk-derived vesicles have no significant effect on RAW264.7 cell proliferation using the cck-8 test (Fig. 3G). Because the level of miR-451 is increased in the colostrum vesicle-treated RAW264.7 cells, we assessed the protein level of its target gene, MIF, and find that the protein level decreased to $46.3 \pm 9.8 \%$ (Fig. $3 \mathrm{H}$ and $3 \mathrm{I}$ ).

In addition, we assessed the impact of the vesicles on phagocytosis and found that the co-incubation of milk-derived vesicles and RAW264.7 cells can increase phagocytosis and that the colostrum-derived vesicles demonstrated a more significant effect (Fig. 4A and 4B). Furthermore, we examined the effect of the vesicles on cell migration and found that pretreatment with the colostrum-derived vesicles can promote cell migration of RAW264.7 cells after stimulation with $100 \mathrm{ng} / \mathrm{mL}$
LPS (Fig. 4C and 4D). Taken together, our results demonstrated that colostrum vesicles have significant effects on immune modulation.

Immune modulatory features were associated with vesicle structure

As we have demonstrated that destroying the vesicle structure by ultrasonication prevented labeled vesicles entering into RAW264.7 macrophages and inhibited the increase of cellular miRNAs (Fig. 1F and 1H), we further tested whether it blocked the following immune modulatory features. We found that all of the observed immune modulatory effects were substantially compromised when the vesicle structure was broken. After ultrasonication, the colostrum vesicles can no longer modulate cytokine production in RAW264.7 macrophages under LPS stimulation (Fig. 3A-C). Furthermore, ultrasonicated colostrum vesicles also lose their effect of significantly promoting phagocytosis or cell migration (Fig. 4A-D). 
A

E

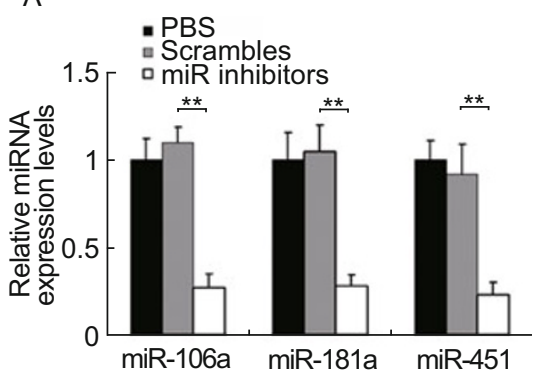

B

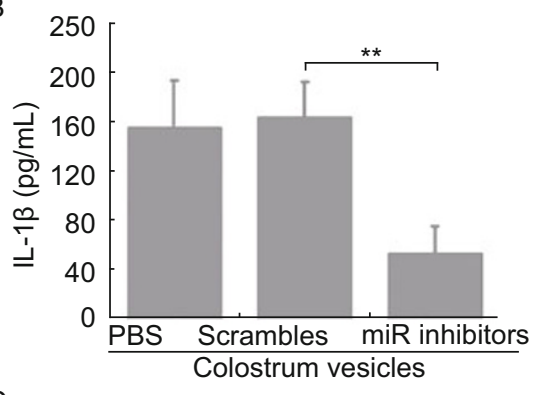

F

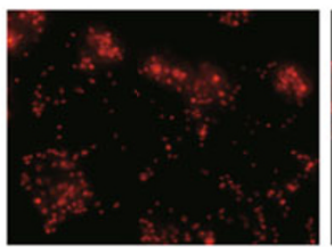

PBS



G
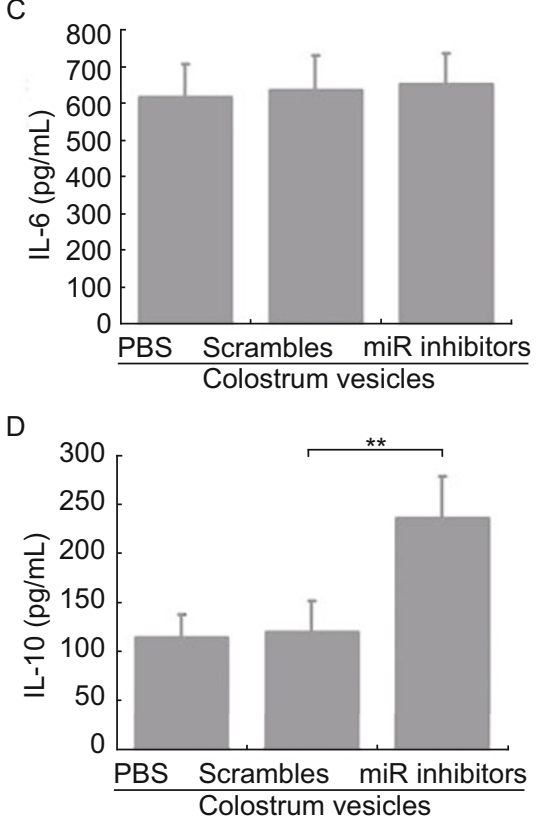

$\mathrm{H}$
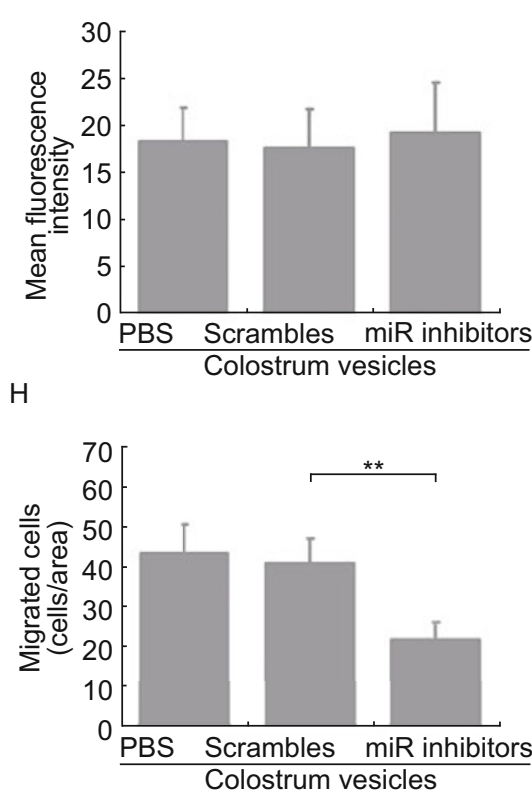

Figure 5. Several immune regulatory effects of colostrum vesicles are compromised after the blockage of miRNAs function with mir inhibitors. (A) miRNAs inhibitors blocked the increase of miRNAs in RAW cells after the treatment of colostrum vesicles. (B-D) Levels of different cytokines secreted by RAW264.7 cells under different treatments after co-incubation with colostrum vesicles. (E and F) Fluorescence image and intensity of phagocytosis rates of RAW264.7 cells under different treatments after co-incubation with colostrum vesicles, scale bar $=10 \mu \mathrm{m}$. $(\mathrm{G}$ and $\mathrm{H})$ Cell migration images and the migratory ability of each group was determined, scale bar $=30 \mu \mathrm{m}$. Scrambles: mixture of random sequence control of miR-106a, miR-181a and miR-451(1:1:1); miR inhibitors: mixture of inhibitors of miR-106a, miR-181a and miR451(1:1:1). ${ }^{*} P<0.01$.

Certain immune modulatory features were associated with immune-related miRNAs transferred via colostrum MVs

To further investigate whether the observed immune modulatory features are associated with the miRNAs transferred by colostrum vesicles, we pre-transfected RAW264.7 macrophages with a pool of miR-106a, miR-181a and miR-451 in- hibitors before co-incubation with colostrum vesicles. We found the miRNAs inhibitors blocked the increase of miRNAs after the treatment of colostrum vesicles (Fig. 5A). In addition, those inhibitors prevented the increase in IL- $1 \beta$ production and the decrease in IL-10 in RAW264.7 macrophages, while showing no effect on IL-6 production (Fig. 5B-D). Furthermore, miRNA inhibitors also blocked the increase of cell migration without 
A



C



D

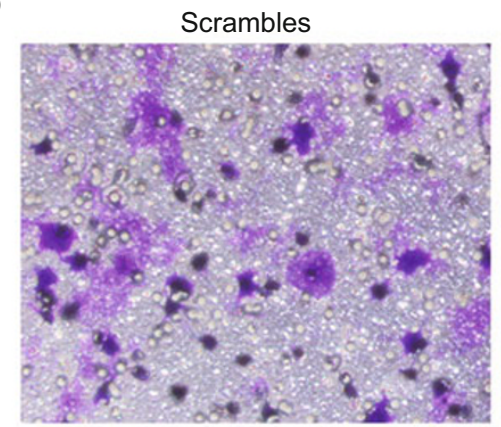

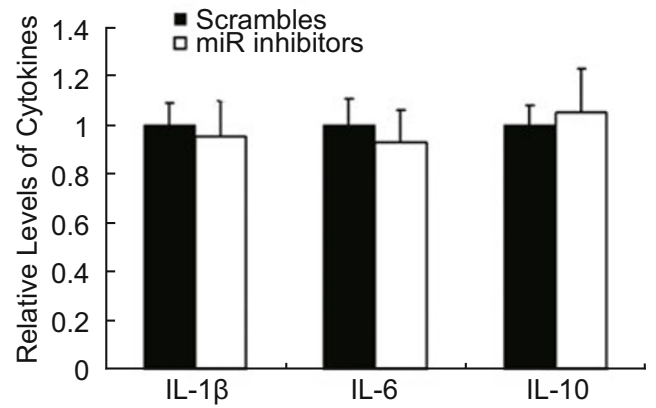

E
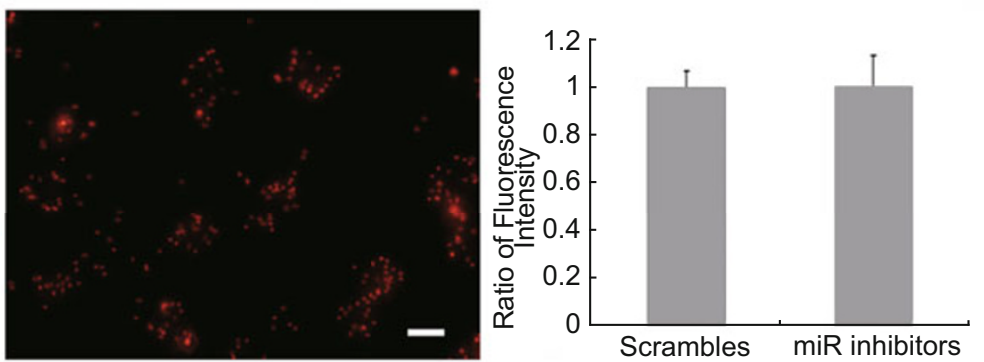

miR inhibitors
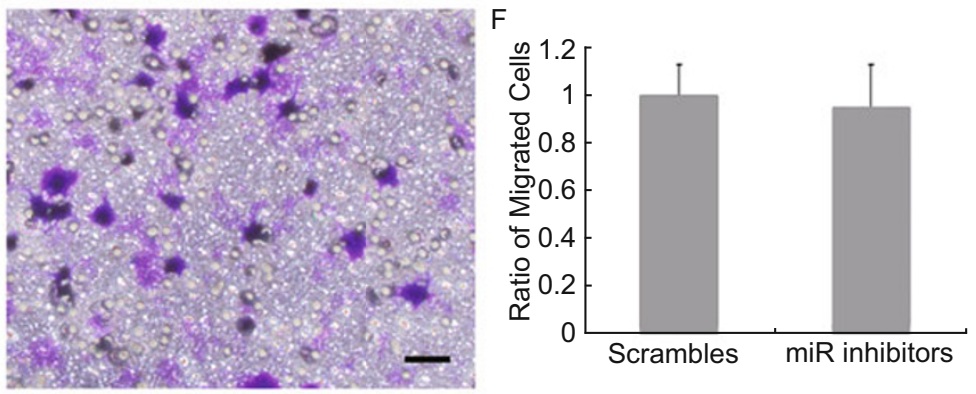

Figure 6. Little effects of miRNAs inhibitors alone on RAW cells immune functions modulation. (A) Relative miRNAs levels in different groups of RAW cells. (B) Relative levels of cytokines production in different groups of RAW cells. (C and D) Fluorescence image and intensity of phagocytosis rates of RAW264.7 cells under different treatments, scale bar $=10 \mu \mathrm{m}$. (E and F) Cell migration images and the migratory ability in different groups of RAW cells, scale bar $=30 \mu \mathrm{m}$.

affecting cell phagocytosis (Fig. 5E-H). These results indicated that there may be other factors in colostrum vesicles rather than miRNAs which are responsible to the change of IL-6 and phagocytosis of RAW cells. Those factors may also have immune regulatory effects. Furthermore, the pool of miRNAs inhibitors alone showed little effects on the cellular function modulation in RAW264.7 macrophages (Fig. 6A-F). This is because the base levels of these three miRNAs in RAW cells are very low and miR inhibitors barely showed any effects in regulating these miRNAs (Table 4).

\section{Colostrum powder-derived vesicles showed similar miRNA patterns and immune modulatory features}

We further assess whether colostrum powder-derived vesicles can affect cell immune function. First, we compare the miRNAs level between colostrum powder vesicles and formula powder vesicles and find that five out of seven miRNAs (miR-24, miR93, miR-106a, miR-181a, and miR-451) were significantly higher in the colostrum powder vesicles than in the formula powder vesicles (Fig. 7A). Next, we investigate whether colostrum powder vesicle can affect the cytokine production of RAW264.7 under $10 \mathrm{ng} / \mathrm{mL}$ LPS stimulation and found that colostrum powder vesicles exhibit similar effects in regulating cytokine production as the colostrum-derived vesicles: the IL$1 \beta$ and IL-6 production were significantly increased, the IL-10 level decreased, and IFN- $\gamma$ and IL-12 levels, TNFa production and cell proliferation were unchanged (Fig. 7B-H). Furthermore, we also demonstrated that the co-incubation of colostrum powder vesicles and RAW264.7 can significantly increase phagocytosis and promote cell migration, which is similar with the results showed in milk-derived vesicles (Fig. 8A-D). 
A



D

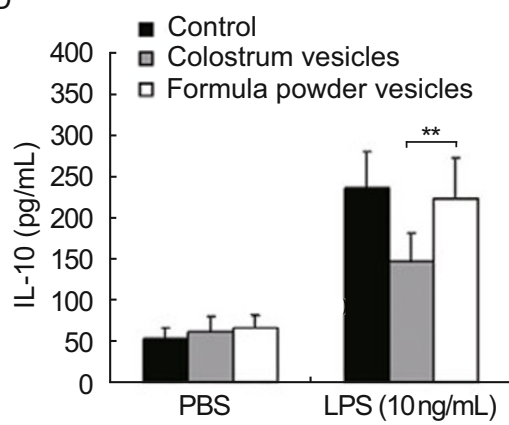

G

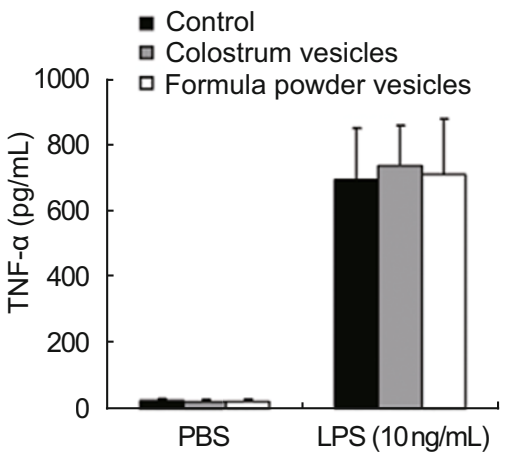

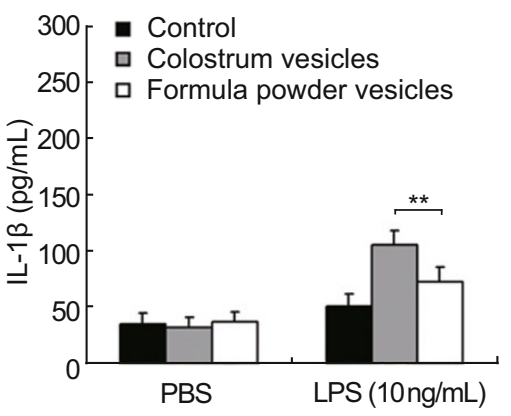

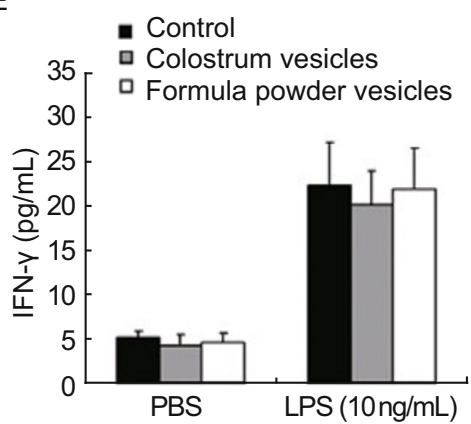

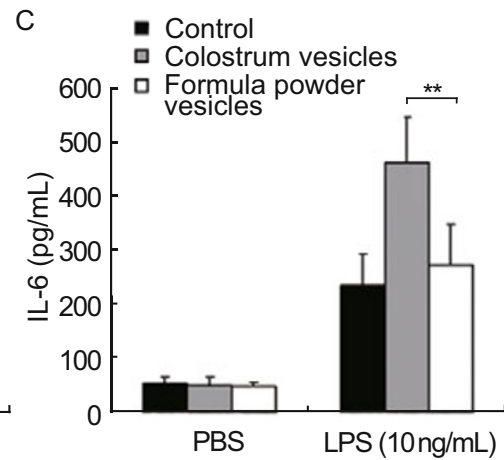

F

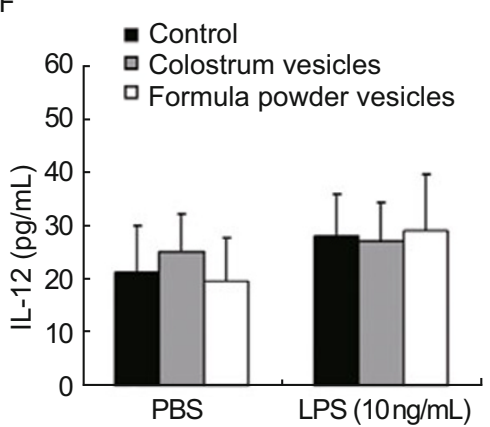

$\mathrm{H}$

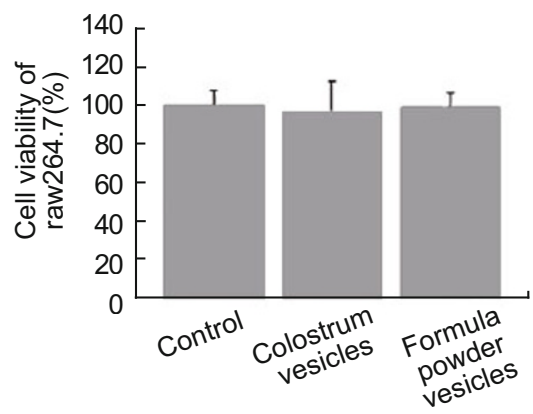

Figure 7. Colostrum powder-derived vesicles showed similar regulatory effects on cytokine production and cell proliferation. (A) Relative miRNAs levels between colostrum powder vesicles and formula powder vesicles. (B-G) Levels of different cytokines secreted by RAW264.7 cells after co-incubation with different milk powder-derived vesicles. $(\mathrm{H})$ Cell proliferation rate measured by ${ }^{c} c k-8 .{ }^{*} P<0.05$; ${ }^{* \star} P<0.01$.

\section{Discussion}

Milk, especially colostrum, has been recognized for its numerous benefits for the developing newborn by providing essential nutrients and immunologically active factors (Kimura et al., 2012). In our previous work, we have demonstrated that milk contains a specific miRNA profile and showed that colostrum have more abundant immune-related miRNAs (Chen et al., 2008). In addition, there are several studies suggesting breast milk also contains high amount of immune related miRNAs which existed in breast milk exosomes (Kosaka et al., 2010; Zhou et al., 2012). Although there are evidences that milkderived vesicles have immune modulatory effects (Admyre et al., 2007), whether these immune regulatory functions are associated with the high amount of miRNAs content still needs further investigation.

In the present study, we systematically compare the expression of immune-related miRNAs between colostrum and mature milk using qRT-PCR and found that seven miRNAs were much higher in colostrum, and of these, miR-24 and miR93 were reported to confer protection from vesicular stomatitis virus infection. In addition, miR-106a and miR-451 were shown to regulate IL-10 and MIF production, respectively (Bandres et al., 2009; Sharma et al., 2009). Furthermore, miR-181a is associated with $\mathrm{T}$ cell sensitivity and selection and the activation of the signal pathway that is involved in the inflammatory response of macrophages (Qin et al., 2010; Oishi and Wang, 2011). Moreover, it is reported that release of miRNAs from 
A



B Control



Colostrum powder vesicles
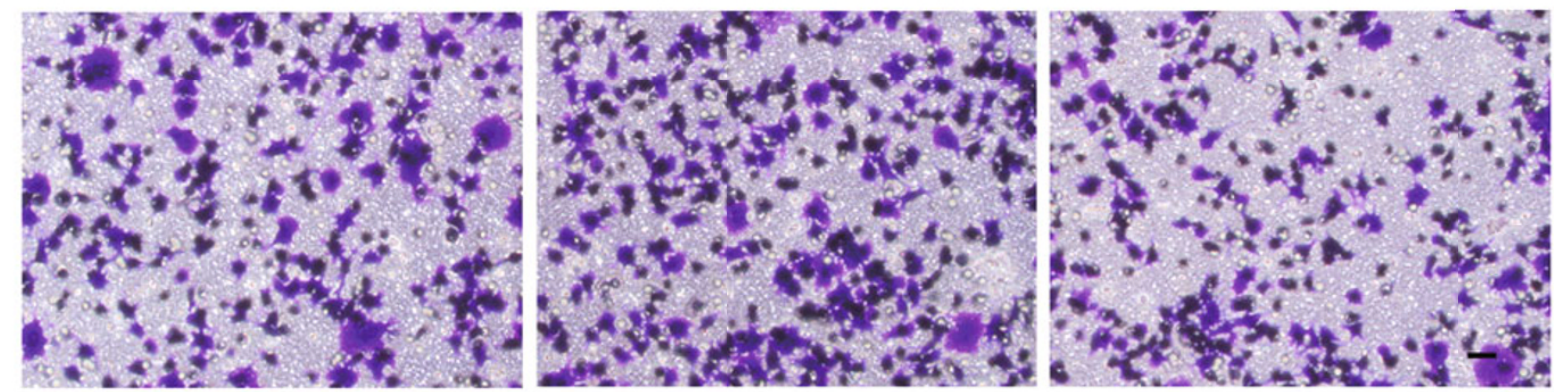

C
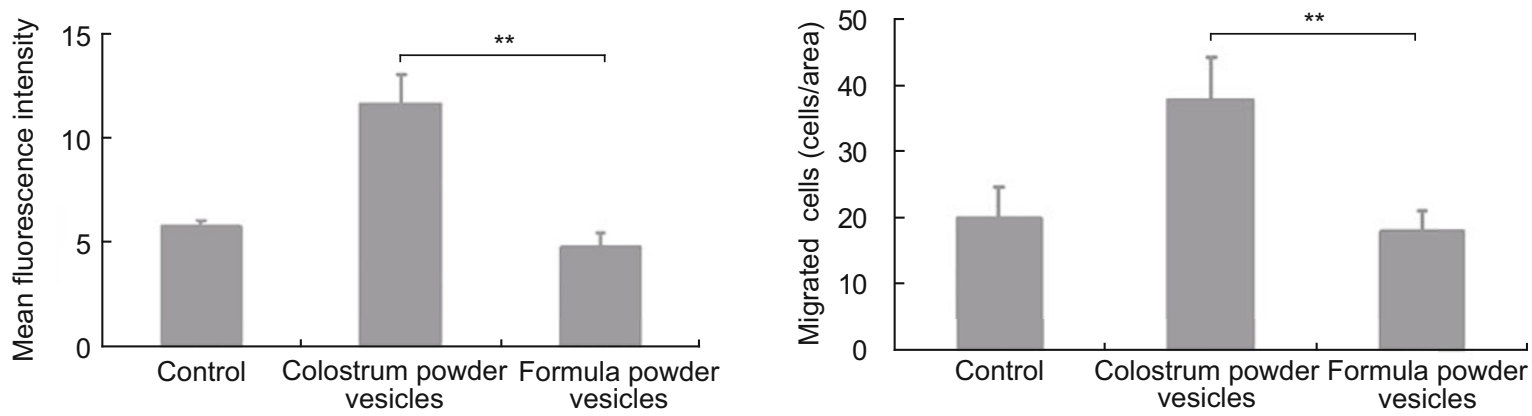

Formula powder vesicles

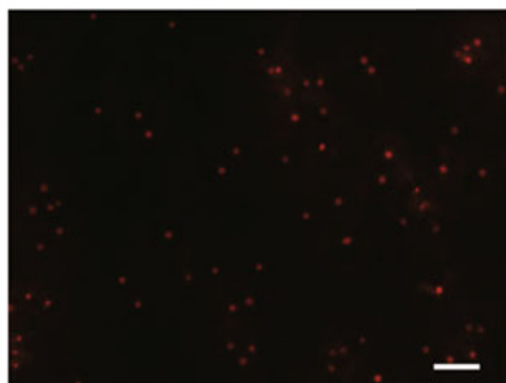

Formula powder vesicles

Figure 8. Colostrum powder-derived vesicles showed similar regulatory effects on phagocytosis and cell migration. (A and C) Fluorescence image and intensity of phagocytosis rates of RAW264.7 cells treated with different groups of milk powder-derived vesicles, scale bar $=10 \mu \mathrm{m}$. (B and D) Cell migration images and the migratory ability of each group was determined, scale bar $=30 \mu \mathrm{m} .{ }^{* \star} P<0.01$.

cells into milk can be selective, which means that high amount of immune related miRNAs in colostrum may be the results of selective secretion by cells with further purpose (Pigati et al., 2010). These data together suggest the possibility that the high amount of immune-related miRNA in colostrum may contribute to its immune modulatory features.

We also provide evidence that the majority of miRNAs were stored in vesicles. As expected, the colostrum vesicles contain higher levels of those seven miRNAs in comparison to mature milk vesicles. It has been proven that milk-derived vesicles can protect small molecules, such as miRNA or mRNA, under conditions that mimic the acidic environment of the gastrointestinal tract and are also capable of transferring small molecules to cultured cells (Chen et al., 2008). In addition, our previous work demonstrated that microvesicles can transfer miRNA between different cells and showed significant biological functions (Fahim et al., 2012). However, there are no direct evidences that milk-derived veislces can deliver miRNAs into target cells. In the present study, we demonstrate that colostrum vesicles have higher levels of the seven immune-related miRNAs and that three of them (miR-106a, miR-181a and miR-451) were significantly increased in cultured cells after co-incubation with the colostrum vesicles. Given that the pre-miRNAs level in cells were unchanged, it is strongly indicated that the elevation of miRNAs in cultured cells is the result of the transfer of miRNAs from the colostrum vesicles. Besides, we also showed that 
fluorescent labeled vesicles can enter into cultured cells after co-incubation. When we destroyed membrane structure of milk derived vesicles, they can neither enter into cultured cells nor increase cellular miRNAs levels, which showed that physical structure of milk vesicles is essential for them to deliver cargos into cultured cells. Together, these data provide strong evidences that milk derived vesicles can transfer miRNAs into cultured cells.

As mentioned above, miR-106a and miR-451 directly targeted IL-10 and MIF, respectively (Bandres et al., 2009; Sharma et al., 2009), and miR-181a is associated with the activation of the Wnt/beta-Catenin pathway in macrophages (Qin et al., 2010; Oishi and Wang, 2011), suggesting that colostrum vesicles may be able to transfer these miRNAs, leading to further immune modulatory effects. Next, we further investigated immune modulatory features, including proliferation, cytokine production, phagocytosis and migration, of the colostrum vesicles on macrophage cells. Our results showed that the colostrum vesicles increase IL-1 $\beta$ and IL- 6 production and decrease the IL-10 level in RAW264.7 cells under stimulation by a low concentration of LPS. In addition, the protein level of MIF in RAW264.7 cells is also decreased after colostrum vesicle treatment. The decrease in IL-10 and MIF protein is consistent with the result that miR-106a and miR-451 are up-regulated in RAW264.7 cells after colostrum vesicle treatment (Sharma et al., 2009). The cell proliferation was unchanged in our treatments, excluding the possibility that the altered cytokines production was due to variability in the cell number. However, the cytokine levels showed no significant differences between the colostrum and mature milk groups when unstimulated or treated with a high concentration of LPS. These data indicated that colostrum vesicles cannot regulate the production of cytokines alone but can increase the sensitivity of immune responses in macrophage cells. Such effect is masked when the cells are under extreme stress condition, such as a high concentration of LPS. Furthermore, we found that the colostrum vesicles can significantly increase cell migration and promote phagocytosis in RAW264.7 cells. Taken together, these results showed that colostrum vesicles have substantial effects in immune modulation.

We also provide strong evidence that the physical structure of the vesicle is essential to the immune modulatory property. Through ultrasonication, we destroyed the vesicle structure and found that the immune modulatory features were significantly compromised. These results indicate that the physical structure of the vesicle is indispensable for transferring small molecules into cultured cells and may lead to further biological functions. Using miRNA inhibitors, we provide evidence that the miR-106a, miR-181a and miR-451 transferred by the colostrum vesicles are directly associated with several immune modulatory effects, including regulating the production of $\mathrm{IL}-1 \beta$ and IL-10 and cell migration. However, the production of IL-6 and phagocytosis was not affected by miRNA inhibitors suggesting there are other factors as well as miRNAs in vesicles, which also have immune modulatory effects to cultured cells.
Finally, we demonstrated that colostrum powder-derived vesicles also contained high amount of immune related miRNAs and have similar immune modulatory effects as colostrum vesicles.

In conclusion, our work showed that colostrum vesicles contain higher levels of immune-related miRNAs, which may contribute to several immune modulatory features when delivered into cultured cells. However, further investigation is required to elucidate the role of these miRNAs in immune responses in vivo.

\section{MATERIALS AND METHODS}

\section{Milk sample preparation}

Raw milk samples were collected under sterile conditions using multiple milking products. A total of 20 cows at 9 months postpartum and 20 cows at 7 days postpartum were recruited, and $1000 \mathrm{~mL}$ of mature milk (taken from the cows at 9 months postpartum) or colostrum (taken from the cows at 7 days postpartum) were collected, respectively. The samples were transported to the laboratory on ice and centrifuged at $1500 \mathrm{~g}$ for $20 \mathrm{~min}$ to remove the cell debris. The supernatant was recovered and stored at $-80^{\circ} \mathrm{C}$ for further analysis. Both colostrum and mature milk were analyzed as pool samples which were used for the following functional study.

Preparation of milk-derived vesicle by differential ultracentrifugation

Milk vesicles are prepared as previously described (14), with several modifications. Briefly, bovine milk samples were centrifuged first at $5000 \mathrm{~g}$ for $30 \mathrm{~min}$ at $4^{\circ} \mathrm{C}$ to remove the milk fat globules (MFGs) and mammary gland-derived cells. The defatted samples were then subjected to 3 successive centrifugations at $4^{\circ} \mathrm{C}$ for $1 \mathrm{~h}$ each at $12,000 \mathrm{~g}, 35,000 \mathrm{~g}$, and $70,000 \mathrm{~g}$ to remove the residual MFGs. The supernatants after the $70,000 \mathrm{~g}$ centrifugation were filtered sequentially through $0.44 \mu \mathrm{m}$ and $0.22 \mu \mathrm{m}$ filters to remove other cell debris. The filtered fraction was then prepared by ultracentrifugation at $100,000 \mathrm{~g}$ for $1 \mathrm{~h}$ to sediment the vesicles. The vesicles from $100 \mathrm{~mL}$ of milk were washed twice and suspended in $1 \mathrm{~mL}$ PBS. The protein contents of vesicle samples were measured by BCA protein assay (pierce). For labeling milk derives vesicles, Dil $(10 \mu \mathrm{g} / \mathrm{mL}$, sigma) were used in $70,000 \mathrm{~g}$ supernatants before $100,000 \mathrm{~g}$ ultracentrifugation, the labeled vesicles were collected and washed twice with PBS before further use. For ultrasonication samples, the suspended vesicles were subjected to $25 \mathrm{kHz}$ ultrasonic vibration (10s for three times) before the following treatment.

\section{qRT-PCR}

qRT-PCR was performed using TaqMan microRNA probes (Applied Biosystems), as previously described (15). Briefly, $5 \mu \mathrm{L}$ of total RNA was reverse-transcribed to produce cDNA using AMV reverse transcriptase (TaKaRa) and stem-loop RT primers (Applied Biosystems). Real-time PCR was performed using a TaqMan PCR kit and an Applied Biosystems 7300 Sequence Detection System (Applied Biosystems). All of the reactions, including the no-template controls, were run in triplicate. After the reactions, the CT values were determined using fixed-threshold settings. To calculate the absolute expression levels of the target miRNAs, a series of synthetic miRNA oligonucleotides of 
known concentrations were also reverse-transcribed and amplified. The absolute amount of each miRNA was then calculated by referring to the standard curve of synthetic miR-16. For the bovine specific gene analysis, primer sets were used according to (Hata et al., 2010).

\section{Statistical analysis}

The qRT-PCR assay was performed in triplicate, and the entire experiment was repeated multiple times. The data shown are presented as the means \pm SEM of three or more independent experiments, and the differences were considered statistically significant at $P<0.05$ using Student's $t$-test.

\section{Incubation of RAW264.7 cells with milk-derived vesicles}

RAW264.7 cells were maintained in DMEM medium with 10\% FBS in a $37^{\circ} \mathrm{C}$ humidified incubator $\left(5 \% \mathrm{CO}_{2}\right)$. Usually, cells were co-incubated with $50 \mu \mathrm{g} / \mathrm{mL}$ milk-derived vesicles or the same amount of PBS (as a control) in complete vesicle-depleted medium for $12 \mathrm{~h}$ (unless indicated). After co-incubation, cells are extensively washed with PBS for three times before the following assessments.

\section{Analysis of phagocytosis of RAW264.7}

After incubation with the milk-derived vesicles, $1 \mu \mathrm{m}$ carboxylatemodified microspheres (Invitrogen) were added, and the macrophages were allowed to internalize the particles for $60 \mathrm{~min}$ at $37^{\circ} \mathrm{C}$. The cells were washed in PBS three times before visualization using red fluorescence with an inverted fluorescence microscope equipped with a DP70 CCD digital camera. After photographing the cells, they were collected for FACS analysis using Cellquest software (BD Biosciences).

\section{Analysis of migration of RAW264.7}

A migration assay was performed using a 24 well chemotaxis chamber with a membrane pore size of $8 \mu \mathrm{m}$. Briefly, the cells were pre-incubated with milk-derived vesicles, and the cells were then stimulated with LPS (100 ng/mL). After $24 \mathrm{~h}$, cells of each group were added to the upper wells of the chamber at $2 \times 10^{4}$ cells per well. The lower wells were filled with DMEM medium with $10 \%$ FBS, and the chamber was then incubated at $37^{\circ} \mathrm{C}$ for $4 \mathrm{~h}$ to initiate migration. Non-migrated cells were wiped off with a cotton swab, and the filter was fixed and stained with Crystal Violet Staining Solution. The number of migrated cells in five random microscopy fields per well was counted at $200 x$ magnification.

\section{Analysis of cytokines by ELISA}

After incubation with milk-derived vesicles, the RAW264.7 cells were stimulated with different concentrations of LPS $(10 \mathrm{ng} / \mathrm{mL}, 100 \mathrm{ng} / \mathrm{mL}$ and $1 \mu \mathrm{g} / \mathrm{mL}$ ) for $6 \mathrm{~h}$ and then washed 3 times with PBS. The next 24 $\mathrm{h}$ cell culture medium was collected for the quantification of different cytokines. Cytokine levels were quantified using an ELISA kit (Beijing 4A Biotech Co., Ltd.) according to the manufacturers protocol.

\section{Electronic microscopy}

After ultracentrifugation, the milk-derived vesicles were precipitated and fixed in $2.5 \%$ glutaraldehyde in $0.1 \mathrm{~mol} / \mathrm{L}$ phosphate buffer and cut into $50 \mu \mathrm{m}$-thick sections using a vibratome. The sections were postfixed with $1 \%$ OsO4, dehydrated, and embedded in Durcupan
(ACM; Fluka, Buchs, Switzerland) on a microscope slide and covered with a coverslip. The sections were further cut using a Reichert ultramicrotome into 70-nm-thick sections. The ultrathin sections were then stained with uranil acetate and lead citrate and evaluated on an electron microscope.

\section{AKNOWLEDGEMENTS}

This work was supported by grants from the National Natural Science Foundation of China (Grant Nos. 30988003, 31071232, 31000323 31000478 and 90608010) and the National Basic Research Program (973 Program) (No. 2011CB504803).

\section{REFERENCES}

Admyre, C., Johansson, S.M., Qazi, K.R., Filen, J.J., Lahesmaa, R., Norman, M., Neve, E.P., Scheynius, A., and Gabrielsson, S. (2007). Exosomes with immune modulatory features are present in human breast milk. J Immunol 179, 1969-1978.

Agarwal, S., Karmaus, W., Davis, S., and Gangur, V. (2011). Immune markers in breast milk and fetal and maternal body fluids: a systematic review of perinatal concentrations. J Hum Lact 27, 171-186.

Bandres, E., Bitarte, N., Arias, F., Agorreta, J., Fortes, P., Agirre, X., Zarate, R., Diaz-Gonzalez, J.A., Ramirez, N., Sola, J.J., et al. (2009). microRNA-451 regulates macrophage migration inhibitory factor production and proliferation of gastrointestinal cancer cells. Clin Cancer Res 15, 2281-2290.

Chen, X., Ba, Y., Ma, L., Cai, X., Yin, Y., Wang, K., Guo, J., Zhang, Y., Chen, J., Guo, X., et al. (2008). Characterization of microRNAs in serum: a novel class of biomarkers for diagnosis of cancer and other diseases. Cell Res 18, 997-1006.

Chen, X., Gao, C., Li, H., Huang, L., Sun, Q., Dong, Y., Tian, C., Gao, S., Dong, H., Guan, D., et al. (2010). Identification and characterization of microRNAs in raw milk during different periods of lactation, commercial fluid, and powdered milk products. Cell Res 20, 1128-1137.

El Gazzar, M., and McCall, C.E. (2012). MicroRNAs regulatory networks in myeloid lineage development and differentiation: regulators of the regulators. Immunol Cell Biol 90, 587-593.

Fahim, M., Millar, A.A., Wood, C.C., and Larkin, P.J. (2012). Resistance to Wheat streak mosaic virus generated by expression of an artificial polycistronic microRNA in wheat. Plant Biotechnol J 2, 150-163.

Feng, R., Zhao, C., Li, M., Harrison, T.J., Qiao, Z., Feng, Y., Ma, Z., and Wang, Y. (2011). Infection dynamics of hepatitis $E$ virus in naturally infected pigs in a Chinese farrow-to-finish farm. Infect Genet Evol 11, 1727-1731.

Hata, T., Murakami, K., Nakatani, H., Yamamoto, Y., Matsuda, T., and Aoki, N. (2010). Isolation of bovine milk-derived microvesicles carrying mRNAs and microRNAs. Biochem Biophys Res Commun 396, 528-533.

Honorio-Franca, A.C., Carvalho, M.P., Isaac, L., Trabulsi, L.R., and Carneiro-Sampaio, M.M. (1997). Colostral mononuclear phagocytes are able to kill enteropathogenic Escherichia coli opsonized with colostral IgA. Scand J Immunol 46, 59-66.

Honorio-Franca, A.C., Launay, P., Carneiro-Sampaio, M.M., and Monteiro, R.C. (2001). Colostral neutrophils express Fc alpha receptors (CD89) lacking gamma chain association and mediate noninflammatory properties of secretory IgA. J Leukoc Biol 69, 289-296.

Huang, S., and He, X. (2010). microRNAs: tiny RNA molecules, huge 
driving forces to move the cell. Protein Cell 1, 916-926.

Huang, Y., Zou, Q., Song, H., Song, F., Wang, L., Zhang, G., and Shen, X. (2010). A study of miRNAs targets prediction and experimental validation. Protein Cell 1, 979-986.

Kimura, M., Oh, S., Narabayashi, S., and Taguchi, T. (2012). Usefulness of lymphocyte stimulation test for the diagnosis of intestinal cow's milk allergy in infants. Int Arch Allergy Immunol 157, 58-64.

Kosaka, N., Izumi, H., Sekine, K., and Ochiya, T. (2010). microRNA as a new immune-regulatory agent in breast milk. Silence 1, 7.

Macchiaverni, P., Arslanian, C., Frazao, J.B., Palmeira, P., Russo, M., Verhasselt, V., and Condino-Neto, A. (2011). Mother to child transfer of $\lg G$ and $\lg A$ antibodies against Dermatophagoides pteronyssinus. Scand J Immunol 6, 619-627.

Oishi, N., and Wang, X.W. (2011). Novel therapeutic strategies for targeting liver cancer stem cells. Int J Biol Sci 7, 517-535.

Patiroglu, T., and Kondolot, M. (2011). The effect of bovine colostrum on viral upper respiratory tract infections in children with immunoglobulin A deficiency. Clin Respir J. doi: 10.1111/j.1752699X.2011.00268.x.

Pigati, L., Yaddanapudi, S.C., lyengar, R., Kim, D.J., Hearn, S.A., Danforth, D., Hastings, M.L., and Duelli, D.M. (2010). Selective release of microRNA species from normal and malignant mammary epithelial cells. PLoS One 5, e13515.

Qin, L., Chen, Y., Niu, Y., Chen, W., Wang, Q., Xiao, S., Li, A., Xie, Y., $\mathrm{Li}$, J., Zhao, X., et al. (2010). A deep investigation into the adipogenesis mechanism: profile of microRNAs regulating adipogenesis by modulating the canonical Wnt/beta-catenin signaling pathway.
BMC Genomics 11, 320.

Sharma, A., Kumar, M., Aich, J., Hariharan, M., Brahmachari, S.K., Agrawal, A., and Ghosh, B. (2009). Posttranscriptional regulation of interleukin-10 expression by hsa-miR-106a. Proc Natl Acad Sci U S A 106, 5761-5766.

Skog, J., Wurdinger, T., van Rijn, S., Meijer, D.H., Gainche, L., SenaEsteves, M., Curry, W.T., Jr., Carter, B.S., Krichevsky, A.M., and Breakefield, X.O. (2008). Glioblastoma microvesicles transport RNA and proteins that promote tumour growth and provide diagnostic biomarkers. Nat Cell Biol 10, 1470-1476.

Sonkoly, E., Stahle, M., and Pivarcsi, A. (2008). MicroRNAs and immunity: novel players in the regulation of normal immune function and inflammation. Semin Cancer Biol 18, 131-140.

Vickers, K.C., Palmisano, B.T., Shoucri, B.M., Shamburek, R.D., and Remaley, A.T. (2011). MicroRNAs are transported in plasma and delivered to recipient cells by high-density lipoproteins. Nat Cell Biol 13, 423-433.

Zhang, L., Hou, D., Chen, X., Li, D., Zhu, L., Zhang, Y., Li, J., Bian, Z., Liang, X., Cai, X., et al. (2012). Exogenous plant MIR168a specifically targets mammalian LDLRAP1: evidence of cross-kingdom regulation by microRNA. Cell Res 22, 107-126.

Zhang, Y., Liu, D., Chen, X., Li, J., Li, L., Bian, Z., Sun, F., Lu, J., Yin, Y., Cai, X., et al. (2010). Secreted monocytic miR-150 enhances targeted endothelial cell migration. Mol Cell 39, 133-144.

Zhou, Q., Li, M., Wang, X., Li, Q., Wang, T., Zhu, Q., Zhou, X., Wang, X., Gao, X., and Li, X. (2012). Immune-related microRNAs are abundant in breast milk exosomes. Int J Biol Sci 8, 118-123. 